\title{
Editorial
}

\section{Prognosis of High Arterial Pressure}

\author{
F. Horace Smirk, M.D., F.R.G.P., F.R.A.C.P.*
}

\begin{abstract}
A LWAYS in clinical medicine the art of prognosis has been highly valued. Some 40 years ago, with few effective remedies available, prognosis was largely the expression of the natural history of unhindered disease. Increased knowledge in recent years has made it necessary to take account of additional factors now known to influence the outcome of a disease process. Where effective means of treatment exist, there may be additional difficulty, for prognosis may be influenced by the choice between alternative methods of treatment. Another factor is that a patient who has recovered from one illness will sooner or later die from another; thus, improvement in the outlook of one disease may increase the expectation of death from other causes. The interrelationships of such conditions as high blood pressure, cerebral-vascular disorders and coronary disease become of great interest in this connection.

Twenty-four years ago life insurance companies ${ }^{12}$ reported a close relationship between the level of the blood pressure, systolic as well as diastolic, and the expected mortality in later life. The causes of death relating most closely to the blood-pressure level of untreated hypertensive patients are cardiovascular and cerebral-vascular disorders. This early work has been confirmed and extended in the recent Build and Blood Pressure Study of the American Society of Actuaries. ${ }^{2)}$
\end{abstract}

Not only is there a relationship between frank hypertension and mortality, but underaverage blood pressures are associated with a better prognosis than those which are of average level. It has long been thought, also, that patients whose blood pressures were always found to be at a high level had a worse prognosis than those whose blood pressures were labile.

The casual blood pressure taken without special precautions is much more variable than the basal blood pressure. The more labile or variable part of the casual blood pressure (casual minus basal) may be termed the supplemental blood pressure. If the basal blood pressure is carried out by a defined technique, ${ }^{3)}$ involving a night's rest in hospital in a single room, with a sedative,

* Research Professor of Medicine, Wellcome Medical Research Institute, University of Otago Medical School, Dunedin, New Zealand. 
and next morning repeated measurement of the blood pressure at about 30 sec. intervals for a period of 10 or $15 \mathrm{~min}$., then the blood pressure of hypertensives and normotensives will be found usually to fall to a level much lower than the casual blood pressure, as ordinarily measured in doctor's office or in hospital. The extent to which the blood pressure falls below the casual blood pressure under these basal conditions is the supplemental blood pressure. The lowest level to which the blood pressure will fall under conditions of moderate sedation, mental and physical rest, but without hypotensive drugs, is the basal blood pressure. An investigation on 245 patients was made in New Zealand, mostly before 1950, when effective hypotensive drugs first became available. It was found that a follow-up of hypertensive patients (from mild to severe degrees) at the end of 8 years indicated there was a close relationship between the level of the basal blood pressure and the expectation of death within the 8-year period.4) It was surprising, however, to find that within this time there was no significant relationship between the mortality and the level of the supplemental blood pressure.

When hexamethonium became available in 1950, it was decided to conduct the pre-treatment investigation of patients in the same way as the patients had been investigated by us before 1950 for our prospective study of prognosis. In particular, basal blood pressures were carried out in a large proportion of the patients.

While it is generally agreed that severe retinal grade III and IV patients are benefitted by hypotensive drug therapy, ${ }^{5-7)}$ there has been much dispute about the less severe cases. ${ }^{5,6), 8)}$ A study of prognosis was made, therefore, in untreated and treated patients, all of retinal grades I or II; all had had a basal blood pressure performed, and all of them had a detailed clinical investigation conducted on similar lines.

It became evident ${ }^{93}$ that the prognosis in untreated patients was related closely to the level of the basal blood pressure, but was not significantly related to the level of the supplemental blood pressure. Simpson and Gilchrist ${ }^{10}$ found a relationship of amytal sleeping blood pressures to prognosis which closely resembled the results of our study on basal pressures. The prognosis in untreated persons was found also to be worse in men than in women, worse in older than in younger decades, worse in those who had already experienced one of a number of hypertensive disabilities than in persons who, at the outset of the follow-up period, had not experienced any of these disabilities. ${ }^{9)}$ The disabilities considered were major stroke, minor stroke, congestive heart failure, coronary artery disease and substantial impairment of renal excretory function. Persons who had experienced two of these disabilities had, as a group, a worse prognosis than those who had experienced only one of them. Where the 
patients had not experienced any of the above-mentioned disabilitics, those who had, nevertheless, got electrocardiographic manifestations, or degrees of breathlessness short of congestive heart failure, had a worse prognosis than those patients who had none of these findings. It became quite evident that a more accurate assessment of prognosis could be made when all of these factors were considered together than when reliance was placed upon blood pressure alone or medical history alone. ${ }^{9)}$

In treated patients of retinal grades I and II the relationship of the basal blood pressure to the 5 -year prognosis is much less definite than in the untreated patients, whereas in both treated and untreated patients there persists a close relationship between the 5-year prognosis and the presence of hypertensive disabilities at the outset of treatment.

Tables were constructed ${ }^{91}$ in which treated and untreated persons were compared who were alike in being of retinal grade I or II, in the level of the basal blood pressure, in sex, in age, and in the number of disabilities (if any) which had been encountered at the initial period of investigation. There is a considerable difference, at the fifth anniversary of the initial investigation, between the percentage mortality of those who received effective hypotensive therapy (14.6 in females, 23.9 in males), and of those who did not (25.4 in females, 44.2 in males). The untreated group as a whole were milder than the treated, because whereas no persons were rejected from the untreated group because they were too mild, only persons considered deserving of treatment entcred the treatcd group. Similar results have been published by Ueda et al.11)

Other work of great interest in this respect has come from Japan, some of which was presented at the recent Asian-Pacific Congress in Kyoto. The natural history of hypertension in Japan differs, in at least one important respect, from that of populations resident in Europe, U.S.A., Australia and New Zealand, namely, that in untreated patients cerebral-vascular disease was the most important cause of death in Japan, ${ }^{12)}$ whereas in Great Britain and the United States congestive heart failure was the most important cause of death in untreated persons.

As hypertension increases the liability to coronary artery disease, it is of interest that with a high incidence of hypertension the incidence of coronary artery disease is appreciably less in Japan than it is in the above-mentioned countries. ${ }^{13), 14\}}$

Further evidence along these lines comes from our experience in New Zealand. Here, in untreated patients before 1950, congestive heart failure and cerebral-vascular disease were the most important causes of death in hypertension. Soon after the introduction of hexamethonium, the mortality 
from congestive heart failure diminished to a great degree, as has been reported by many authors. ${ }^{15)}$

In our hypertensive clinic we noticed, however, that very severe cases who, in the absence of hypotensive drugs, might have been expected to die from heart failure, when on hypotensive drug treatment recovered from heart failure but had a high mortality from cerebral-vascular accidents later, and deaths from this cause became, for a time, the main cause of death in treated hypertensive patients. The New Zealand national statistics in 1951 and 1952 showed a rise in death rate from cerebral-vascular accidents, while other deaths attributed to hypertension decreased.

Later, with improved methods of treatment, we obtained evidence in our hypertensive clinic of a reduction in the mortality from strokes. ${ }^{7)}$

Our annual mortality at present is approximately $5 \%$ per annum of our hypertensive clinic population, which is attended now by about 700 patients. During the last 6 years there has been a considerable increase in the proportion of treated hypertensive patients dying from proved and presumed coronary artery discase, and from such irrelevant causes as carcinoma, with a corresponding decrease in the proportion of other deaths. ${ }^{16)}$ Thus, comparing deaths in untreated hypertensives, deaths in our treated group up to December 1958, and deaths in treated groups of 1959 to 1964, the percentages of deaths attributable to coronary artery disease or sudden death probably due to coronary artery disease were respectively 17.1, 19.2 and 42.5, and those attributed to causes unconnected with the hypertension rose from under $8 \%$ in untreated persons to 17.3 in the patients who died while on treatment in the last 6 years. ${ }^{17)}$

This observation may be considered in relationship to the autopsy study on virtually untreated patients by Clawson, ${ }^{18)}$ who found that hypertensive patients dying from causes other than coronary artery disease such as stroke had, in a very high proportion, clear-cut evidence of coronary artery disease present at autopsy. This raises the question of whether very early treatment would retard the development of coronary artery disease in hypertensive patients.

It seems likely that in a coronary-prone environment a considerable reduction in the hypertensive mortality from other causes may be cxpected to be associated with an increase in the proportion of deaths from coronary artery disease in the hypertensives. It will be most important to observe what changes take place in the mortality of treated hypertensives in countries such as Japan, where the principal cause of death in hypertensives is from cerebralvascular disease, and where coronary artery disease is less frequent than in New Zealand, Australia and western countries. Although cerebral-vascular 
accidents are more prevalent among those whose blood pressures are high, they occur also in normotensives. It is hardly to be expected that improvements in the treatment of hypertension will make it possible to eliminate this cause of death; it may, nevertheless, reduce it considerably. So far the percentages of our hypertensive mortality due to strokes are: in untreated hypertensives up to December 1958, 39.6, in treated hypertensives up to December 1958, 33.1, and in treated hypertensives 1959 to $1964,22.0$.

\section{Personal Gommunication Attached}

Dear Dr. Ueda,

Enclosed you will find material for an editorial entitled "Prognosis of High Arterial Pressure".

I chose this subject because I felt that a comparison of the changes in the prognosis in hypertension in New Zealand and Japan might perhaps be of interest to Japanese readers. I am very much interested in the possibility that in the long run the degree of improvement which may be obtained in the treatment of hypertensives may be appreciably greater in Japan than in countries with a much higher incidence of coronary artery disease.

With the kindest possible regards, Yours sincerely,

F. Horace Smirk

\section{References}

1. Supplement to Blood Pressure Study: The Actuarial Society of America and the Association of Life Insurance Medical Directors, New York, 6, 1941.

2. Build and Blood Pressure Study: Society of Actuaries, Chicago, I, II : 1959.

3. Smirk, F. H. : Brit. Heart J. 6 : 176, 1944.

4. Smirk, F. H., Veale, A. M. O., and Alstad, K. : N. Z. Med. J. $58:$ 711, 1959.

5. Rosenheim, M. L. : Brit. Med. J. ii : 1181, 1954.

6. Barnett, A.J.: Aust. Ann. Med. 5 : 274, 1956.

7. Hodge, J. V., McQueen, E. G., and Smirk, F. H. : Brit. Med. J. i : 1, 1961.

8. Grollman, A.: Clin. Res. Proc. 2: 159, 1954.

9. Smirk, F.H. : N. Z. Med. J. $63: 413,1964$.

10. Simpson, F. O. and Gilchrist, A. R. : Scot. Med. J. 3: 1, 1958.

11. Ueda, H., Nakajima, K., Takeda, T., and Ikeda, T. : Jap. Heart J. 5: 399, 1964.

12. Sassa, K.: Jap. Heart J. 3 : 203, 1962.

13. Kimura, N.: In "World Trends in Cardiology", ed. Keys and White, Hober-Harper, New York, 22-33, 1956

14. Ueda, H.: Am. J. Cardiol. 10:371, 1962.

15. Smirk, F.H.: High Arterial Pressure. Blackwell, Oxford, 692, 1957.

16. Smirk, F. H. and Hodge, J. V.: Brit. Med. J. 2 : 1221, 1963.

17. Smirk, F. H. and Hodge, J. V.: unpublished.

18. Clawson, B. J. : In "Hypertension", ed. Bell, University of Minnesota Press, Minneapolis, 248,1951 . 